\title{
Design and realization of wireless remote calibration system of ship-craft
}

\author{
Gao-Feng Pan, Si-Fang Liu ${ }^{\dagger}$, Cheng-Bin Zhou and Sheng Liang \\ China Satellite Maritime Tracking and Control Department, \\ Jiangyin 214431, China; \\ liumaster2006@163.com \\ *Corresponding author: Si-Fang LIU
}

\begin{abstract}
To improve the orbit determination precision of the TT\&C equipment, the equipment parameters need to calibrate accurately using the calibration tower during the dock calibration. Through comparing the remote control mode and analyzing the control object, this paper builds the wireless communication environment using ZigBee technology, through developing the hardware circuit and control software, it realizes the remote monitoring for the calibration equipment/facilities and instruments. The test results show that the monitoring system is reliable with communication, convenient operation, it solves the shortcomings to artificial mode, as communication inconvenience, flawed conditions, low efficiency, etc, his system makes an important contribution for finishing the dock calibration work efficiently and reliably.

Keywords: Dock calibration; Wireless monitoring; UDP
\end{abstract}

\section{Introduction}

With the development of China's aerospace industry, ship-borne system is also equipped with a unified control system for x-band, due to the higher frequency, antenna aperture larger, angle calibration problems that need to be solved. Far-field conditions to meet the calibration[1][2], and elevation angles greater than $7^{\circ}$ requirements need to be from the ship, about 8000 meters, height of about $1000 \mathrm{~m}$ architecture provides an $\mathrm{x}$-band beacon, used to standardize cross-coupling, directional sensitivity and check for servo tracking performance. Through research using airships carry beacons program for equipment calibration. To achieve the target, capture and improve calibration task usage, airship location information needs to be collected, and can control the x-band beacon. To achieve the target, capturing and enhancing utilization of calibration, the airship location information needs to be collected, and can control the $\mathrm{x}$-band beacon.

Designed a remote wireless control system for boats-boats, through the design of appropriate modules to build channels for uplink and downlink, airship 
destination information can be accomplished settlement and x-band beacon frequency control and meet the requirements of system calibration.

\section{System Scheme}

\subsection{Analysis of control objects}

System control for the x-band beacon, you can implement any frequency within the frequency band setting. However, airship stronger during takeoff, x-band equipment becomes saturated, cannot make proper tracking, you need to guide and to ensure data processing needs, and blimp are also required to provide accurate location information. Obviously, the information content of the system consists of two parts, one is the command information for real-time control beacon frequency; the second is location, for shipborne servo guide and data processing.

\subsection{Control mode selection}

Boats-boat information interaction system based on wireless communication technology[3], it is the use of the characteristics of electromagnetic wave propagation in free space a communication way to exchange information, is the information and communication field in recent years the fastest, one of the most widely used technologies. According to application occasions of different, achieved wireless communications of means technology very more, and applies $\mathrm{Yu}$ this system of communications way main including GSM/GPRS, and number biography radio, and satellite communications, and control communications, which satellite communications is refers to in airship Shang configuration corresponding equipment, using ship contains of SATCOM for communications; control communication refers to the configuration $\mathrm{x}$-band transponder device on the airship, through telemetry, remote monitor and control link shipborne equipment..

Table 1. Common wireless communication mode

\begin{tabular}{|c|c|c|c|c|}
\hline $\begin{array}{c}\text { Wireless } \\
\text { communication }\end{array}$ & Communication distance & Real-time & $\begin{array}{l}\text { Developme } \\
\text { nt costs }\end{array}$ & $\begin{array}{l}\text { Operating } \\
\text { costs }\end{array}$ \\
\hline GSM,GPRS & $\begin{array}{l}\text { Constrained by the antenna } \\
\text { performance }\end{array}$ & No & Low cost & Low cost \\
\hline Digital radio & To be more than $1 \mathrm{~km}$ & Yes & Low cost & None \\
\hline $\begin{array}{c}\text { Satellite } \\
\text { Communications }\end{array}$ & Unrestricted & Yes & Cost is high & $\begin{array}{l}\text { Cost is } \\
\text { high }\end{array}$ \\
\hline $\begin{array}{c}\text { TT\&C } \\
\text { communication }\end{array}$ & $\begin{array}{l}\text { Associated with the communi } \\
\text { cation distance }\end{array}$ & Yes & Cost is high & Low cost \\
\hline
\end{tabular}


Through analysis we can see that, for this high number of wireless communication system most suitable for radio. According to the comprehensive consideration of the communication distance and data rate, select United States of MDS TRM module for building wireless links. The module in the $220 \sim 240 \mathrm{MHz}$ frequency range, using GMSK modulation, the maximum output power $2 \mathrm{~W}$, ensuring effective communication distance of $50 \mathrm{~km}$ and has super small volume and SPI interface for easy system integration.

\section{System Hardware}

System principle block diagram is shown in figure 1 , the system is mainly composed of airship control terminal and ship control. According to the system function, the airship control comprised X band beacon, GPS module, the data transmission module, control module and the corresponding antenna, the core components for the control module; Ship control comprised digital module, control module, system monitor, servo subsystem and receiving subsystem of the core components for the system monitor.

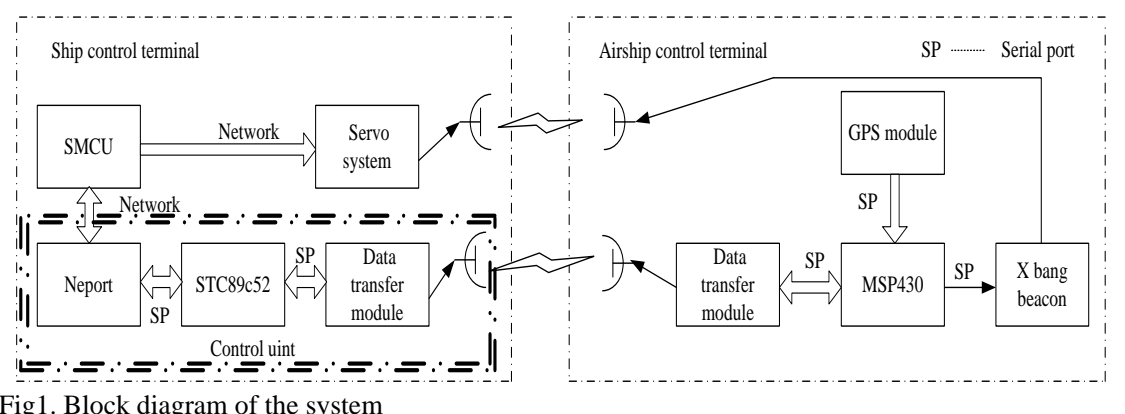

Fig1. Block diagram of the system

\subsection{Design of the airship terminal}

According to the airship control device interfaces, control module needs to provide dual serial port, master chip selects MSP430F149[4] micro machines, it has a hardware multiplier and 48 I/O ports, 10 timers, 2 USART ports and RAM up to $60 \mathrm{~KB}$ Flash, $2 \mathrm{~KB}$, peripheral circuits, electrical schematic diagram is shown in Figure 2. MSP430F149 MCU USART1 receive GPS data, and packets sent, which use Holux GPS module M-9329; USART2 to communicate with the $\mathrm{x}$-band Beacon Receiver, complete the frequency control of $\mathrm{x}$-band Beacon Receiver. Log-radio control is done through the SPI bus module control, time series data with SPI Control transceiver. 


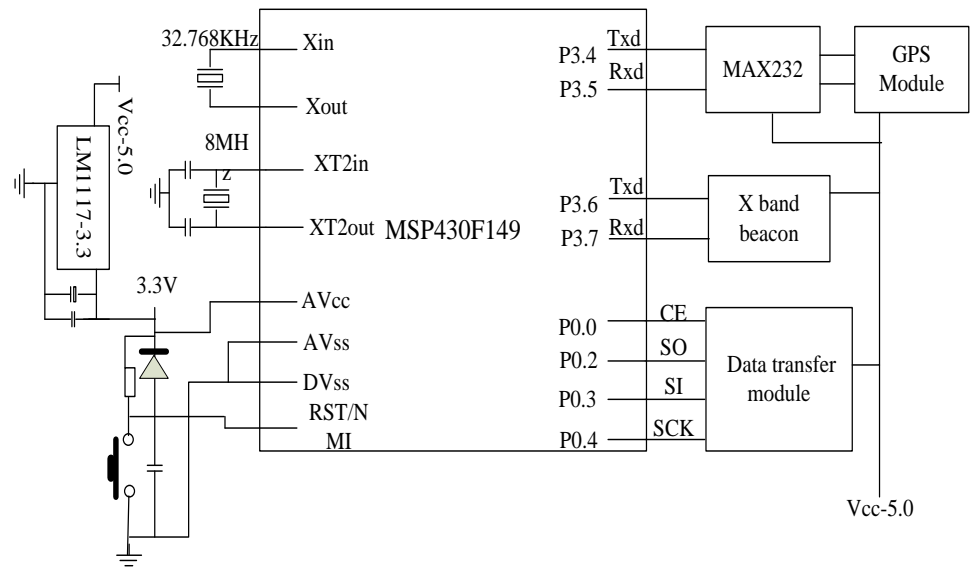

Fig2. Airships side control module electrical schematic

\subsection{Design of Shipborne Terminal}

In Figure 1, the double dotted line section for the new device-control unit, the master chip using STC89C52[5] MCU, the electrical schematic and airship port is basically the same.STC89C52 single-chip computer controlled digital radio through the SPI[6] bus; and system control interface with network interface, in order to reduce the difficulty of hardware design, network interface using Neport module through Neport microcontroller to a serial data into UDP network data.

\subsection{Software Design of Hardware}

Software design of hardware circuit and software functions are basically the same, the main serial port configuration and communication timing control and communication, SPI bus, design is modular in design, divided into initializing modules, serial and SPI module, through the features need to be set for each module, to data acquisition and control peripherals.

\section{Design of Monitor Software}

The function of the monitoring computer software design mainly includes the coordinate change, according to the position of receiving the information generated azimuth and elevation of the deck department data, as servo lead data to track the airship, until realizing antenna tracking; According to the requirements of the equipment testing, sending frequency control instruction, set the $\mathrm{x}$-band on the airship beacon, frame format for FF aa bb cc dd FE, the FF for frame head; aa for integer frequency part of the top two; After bb for frequency integer part two; cc for frequency before the decimal part two; The dd for 
frequency after the decimal part two; FE to frame the tail, the software of signal process is shown in figure 3 .

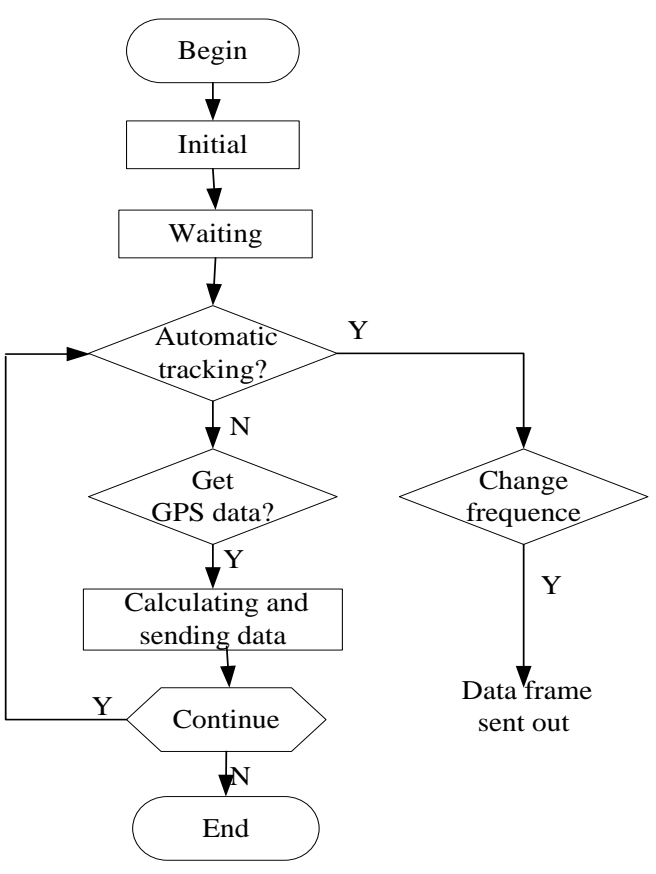

Fig3. Flow chart of software

System monitoring is the core of ship-borne equipment monitoring, has become a reality, including the servo system of system monitor, and means of communication for UDP multicast. As a function of the complete system, improvement of adaptability are needed, the new Socket class, complete with onboard control module of the network communications; new coordinates transformation class to complete location information of coordinate transformations, which are the focus of software design, settlement consists of four steps.

1.Earth centered earth fixed system is converted to INS horizon system $\left[\begin{array}{l}\mathrm{x} \_d p \\ \mathrm{y} \_d p \\ z_{-} \text {dp }\end{array}\right]=\left[\begin{array}{ccc}-\sin \varphi \cos \lambda & -\sin \varphi \sin \lambda & \cos \varphi \\ \cos \varphi \cos \lambda & \cos \varphi \sin \lambda & \sin \varphi \\ -\sin \lambda & \cos \lambda & 0\end{array}\right]\left[\begin{array}{l}\mathrm{x} 1-\mathrm{x} 0 \\ \mathrm{y} 1-\mathrm{y} 0 \\ \mathrm{z} 1-\mathrm{z} 0\end{array}\right]$

$\left[\begin{array}{l}\mathrm{x} 0 \\ \mathrm{y} 0 \\ \mathrm{z} 0\end{array}\right]\left[\begin{array}{l}\mathrm{x} 1 \\ \mathrm{y} 1 \\ \mathrm{z} 1\end{array}\right]$

In formula (1), $\left.\mathrm{z}_{0}\right]$ is coordinate of ship in WGS-84; $\left.\mathrm{z} 1\right]_{\text {is coordinate of }}$ 
object in WGS-84.

2. INS horizon system is converted to INS deck system

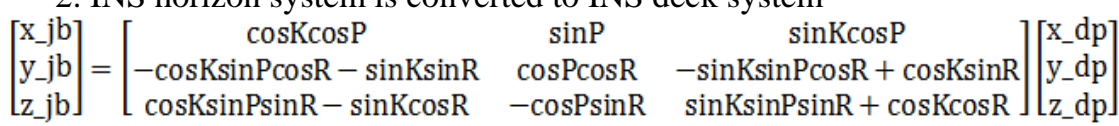

\section{$\left[\begin{array}{l}x_{-} j \mathrm{~b} \\ \mathrm{y}_{-} \mathrm{jb}\end{array}\right]$}

In formula (2), $\left[z_{-} j \mathrm{~b}\right]_{\text {is }}$ coordinate of object in INS deck system;K,P,R is heading, pitch and roll of INS.

3. INS deck system is converted to equipment measurement system

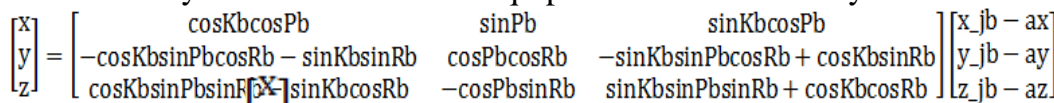

y

In formula (3), $\left.\mathrm{Z}_{\mathrm{Z}}\right]_{\mathrm{is}}$ coordinate of object in equipment measurement system;

ax,ay,az is coordinate of original point for equipment measurement system in INS deck system(known constant); $\mathrm{Kb}, \mathrm{Pb}, \mathrm{Rb}$ is inertial navigation and the deformation of the measurement equipment between stem scratching, rocker and transverse twist.

4. Finally, From the Cartesian coordinates to polar coordinates, to generate boot data to the servo to complete the self-tracking.

\section{Summary}

According to the urgent needs of shipborne angle $\mathrm{x}$-band monitoring and control system calibration by program designed to determine the use of digital radio beacons carried airship x-band. The system functional requirements, are designed airship terminal and ship terminal control unit, adaptive transformation of the system by monitoring software, and ultimately in the system monitoring station to complete the bootstrap servo system and frequency control requirements. System testing shows that have real-time, convenient control, scalability, etc., which has a certain reference designing ideas for the development of other similar control areas.

\section{References}

[1]. Zhong De'an Zhang Tongshuang. Study on Dynamic Calibration Method for Instrumentation Ship at Whart [J].Journal of Spacecraft TT\&C Technology 2010(05). (In Chinese)

[2]. Mang Zhiqiang. Range of Geodesy [M].Beijing: National Defense Industry Press, 2004. (In Chinese) 
[3]. Wang Yonghua. Fieldbus Technology and Application Guide [M].Beijing: Machinery Industry Press, 2008. (In Chinese)

[4]. TI.CC2530 Data sheet [EB].Texas Instruments, Inc. San Diego, California USA, 2007.

[5]. TI.CC2591 Data sheet [EB].Texas Instruments, Inc. San Diego, California USA, 2007.

[6]. Huang Yuli. Design of Node communication module based on CC2531+CC2591 [J]. Microcontroller and Embedded Systems, 2011, 1:71-73. (In Chinese) 